\title{
Disinhibition and Detachment in Adolescence: A Developmental Cognitive Neuroscience Perspective on the Alternative Model for Personality Disorders
}

\author{
Timothy A. Allen ${ }^{a}$ Michael N. Hallquist ${ }^{b}$

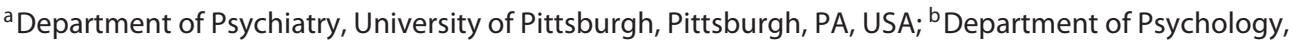 \\ Pennsylvania State University, University Park, PA, USA
}

\section{Keywords}

Personality disorder $\cdot$ Neuroscience $\cdot$ Alternative Model for Personality Disorders · Development

\begin{abstract}
Personality pathology often emerges during adolescence, but attempts to understand its neurocognitive basis have traditionally been undermined by problems associated with the categorical classification of personality disorders. In contrast, dimensional models of personality pathology, such as the Alternative Model for Personality Disorders (AMPD) in DSM-5, may provide a stronger foundation for neurobiological investigations of maladaptive individual differences in personality. As an example, we review studies of the adolescent development of reward processing and cognitive control and connect these systems to the normal personality hierarchy and to two dimensions included in the AMPD - Detachment and Disinhibition. We argue that by linking developmental changes in these systems to the AMPD, researchers will be better positioned to understand the relationship between neurocognitive development and the expression of personality pathology in adolescence and early adulthood.

(c) 2020 S. Karger AG, Basel
\end{abstract}

Personality pathology often emerges and is most severe during adolescence [1]. In parallel, adolescence is characterized by widespread neurocognitive changes that influence reward processing, risk preferences, social behavior, and self-control [2]. Unfortunately, attempts to understand the links between personality dysfunction and brain development during adolescence have been stifled by the categorical classification of personality disorders (PDs) in the Diagnostic and Statistical Manual of Mental Disorders (DSM-5) [3]. Problems with categorical PDs are well-known, including the use of arbitrary boundaries to distinguish between normal and abnormal functioning, excessive comorbidity, and within-disorder heterogeneity [4].

The Alternative Model for Personality Disorders (AMPD), codified in Section III of DSM-5 [3], provides a dimensional alternative to the existing categorical PD nosology. Within the AMPD, PD diagnoses are made on the basis of (a) impairments in self and interpersonal functioning, and (b) ratings on 25 maladaptive personality traits, which can be arranged hierarchically to resemble pathological variants of the Big Five [5].

The merits and limitations of the AMPD have been articulated elsewhere [6-8], so we do not review them

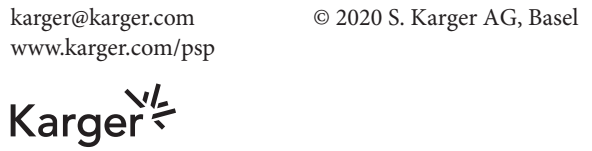


here. Instead, we summarize specific findings from developmental cognitive neuroscience and examine their relevance for understanding normal personality dimensions and the AMPD. Furthermore, we argue that relative to $\mathrm{PD}$ categories, the AMPD provides a better foundation for interpreting and conducting neuroscientific studies of personality pathology, for several reasons. First, the AMPD removes arbitrary boundaries between normal and abnormal functioning, building on robust evidence that personality pathology reflects maladaptive variation in the same trait dimensions as normal personality [9]. Moreover, major traits in the normal personality hierarchy and the AMPD are conserved across species [10] and reflect neurobehavioral systems that have evolved to meet specific adaptive challenges [11]. Consequently, the AMPD may aid neuroscientific research by providing phenotypic targets that are more directly related to the organization of neural systems underlying normal and abnormal personality.

Another key feature of the AMPD is that it does not discourage the assessment of personality pathology symptoms in youth. By contrast, the DSM's categorical model advises against pediatric PD diagnoses except in "relatively unusual instances" [3, p. 647], even though numerous developmental studies have provided compelling evidence that personality pathology does not suddenly express itself at age 18 [12]. This language likely contributes to the underdiagnosis of PDs in youth and hinders research on developmental antecedents [13]. Personality pathology is the product of complex developmental pathways that begin early in life and influence subsequent adaptation and maladaptation $[14,15]$. By advancing a trait model that has reasonable continuity over the lifespan, the AMPD can facilitate neuroscientific research examining how biological processes (e.g., puberty) interact with environmental and sociocultural factors to shape the development of personality.

Finally, consistent with a developmental psychopathology perspective, the AMPD acknowledges that healthy and disordered personality functioning are largely governed by the same processes and mechanisms [16]. As a result, research on the biological and environmental processes that drive typical development can help to uncover the origins of personality pathology, just as studies of personality pathology can yield insights into healthy adaptation.

Below, we review contemporary studies of reward processing and cognitive control in adolescence and consider their points of convergence with the personality neuroscience and personality development literatures. We then consider how maladaptive or extreme variation in typical adolescent neurocognitive development might be conceptualized within the AMPD, focusing specifically on Detachment and Disinhibition.

\section{Neurocognitive Development in Adolescence: Reward Processing and Cognitive Control}

During adolescence, youths navigate an array of new developmental tasks, from pursuing intense social and romantic relationships to exploring nascent autonomy [17]. Such experiences, coupled with neurocognitive development, contribute to an important period of plasticity in personality development [18]. For example, risktaking increases in late adolescence, including drug and alcohol use, as well as risky sexual behavior [19]. Adolescents also become more sensitive to social evaluation [20]. For some, the changes that accompany adolescence can reveal or exacerbate existing vulnerabilities. Indeed, rates of personality pathology and other forms of psychopathology are elevated in adolescence $[1,21]$, as are other serious outcomes including non-suicidal self-injury and suicide attempts [22].

Although several accounts of adolescent changes in personality and behavior have been proposed, dual systems models are especially popular [23]. There are important variations in dual systems models, but all share a common emphasis on the development and relative balance of two neurocognitive systems: a socioemotional reward processing system that peaks during adolescence and a cognitive control system that strengthens gradually with age.

\section{Adolescent Reward Sensitivity: Linking Dual Systems Accounts to Normal Personality}

Within the normal personality literature, individual differences in reward sensitivity typically fall within the domain of Extraversion, which describes individuals who are enthusiastic, gregarious, assertive, and sensationseeking. Maladaptive forms of Extraversion are included within the AMPD under the Detachment domain, which encompasses pathologically low positive emotionality (i.e., anhedonia) and introversion (i.e., intimacy, social avoidance) [24].

A key tenet of dual systems models is that reward sensitivity increases with development, reaching a peak in adolescence before declining or potentially plateauing 
into adulthood [23]. Longitudinal research has not typically found age-related increases in Extraversion during adolescence, with several studies reporting a decline (e.g., Soto [25]). However, it is important to recall that personality traits have a hierarchical structure, such that broader traits account for patterns of covariation among more specific traits. Specific facets of Extraversion show divergent developmental trajectories [26], such that those most closely related to dopaminergic functioning, including sensation-seeking and social dominance, actually increase during the adolescent years [27-29].

Findings from fMRI studies typically support the dual systems perspective. For example, ventral striatum activation during reward processing peaks in adolescence and is positively associated with risk-taking behavior [30, 31]. Likewise, a broader valuation network encompassing the ventral striatum, ventromedial prefrontal cortex, and medial prefrontal cortex is more responsive to reward receipt among late adolescents than children or adults [32].

Reward-related striatal activation partly reflects dopaminergic inputs from the midbrain ventral tegmental area (VTA) [33, 34]. In animal studies, mesolimbic dopamine activity increases following unpredicted rewards and decreases following unpredicted omissions of reward $[35,36]$. This pattern of activity has been called a reward prediction error (RPE) signal, which helps one to learn the subjective value of different stimuli and choose behavioral responses accordingly [37]. In humans, striatal RPEs elicited during a reward task peak during adolescence [38], though not all studies find this, potentially due to task differences or sample size [39]. Pre-adolescent and adolescent participants also show heightened functional coupling between the VTA and ventral striatum within incentivized contexts. This coupling declines with age as a function of decreasing cue-related activation of the orbitofrontal cortex [40], a region that encodes reward value and stimulates dopaminergic transmission via direct inputs to the VTA [41]. Taken together, this evidence points to a temporary increase in dopaminergic neurotransmission during adolescence, which may contribute to enhanced reward sensitivity.

Inputs from other cortical and subcortical areas to the striatum are also involved in modulating adolescent reward sensitivity. A recent meta-analysis of reward processing found that relative to adults, adolescents show greater activation in the ventral and dorsal striatum, as well as functionally connected regions, including the insula, amygdala, orbitofrontal cortex, and the anterior cingulate cortex (ACC) [31]. Developmental changes in the connectivity between these regions and the striatum ap- pear to mirror changes in reward sensitivity. For example, connectivity between the ventral striatum and ventromedial prefrontal cortex declines with age and mediates developmental reductions in pleasure ratings following reward [42]. Likewise, the structural integrity of limbic inputs to the striatum declines during the transition to adulthood, coinciding with age-related reductions in the enhancement of cognitive performance by rewards [43].

Neurobiological research on Extraversion mostly converges with the dual systems literature. Specifically, Extraversion moderates the efficacy of pharmacological manipulations of the dopamine system, is associated with heightened activity in the ventral striatum during reward anticipation, and has been linked to increased functional connectivity between the dopaminergic midbrain and striatum $[26,44]$. Furthermore, increases in the volume and activity of the ventral striatum are prospectively associated with increases in Extraversion during adolescence $[28,45]$. Finally, several studies have shown that Extraversion is associated with the reward-related positivity, an event-related potential that spikes following feedback about an outcome and likely encodes an RPE produced by midbrain dopaminergic inputs to the striatum and ACC [46, 47]. Interestingly, the amplitude of the reward-related positivity increases in response to gains, but not losses, as children transition into adolescence, consistent with the prediction of dual systems models [48].

\section{Maturation of Inhibitory Control and Concomitant Increases in Conscientiousness}

Cognitive control involves the capacity to guide one's behavior flexibly and voluntarily, which requires both working memory and inhibitory control (or the ability to suppress disruptive impulses) [49]. Within the personality literature, cognitive control is closely related to Conscientiousness, a trait that describes those who are persistent, planful, and orderly ${ }^{1}$. Much like cognitive control, Conscientiousness has been hypothesized to facilitate the pursuit of long-term goals and promote rule-based behavior, both of which rely on the ability to avoid distractions and suppress disruptive impulses [50]. Maladap-

\footnotetext{
1 Working memory components of cognitive control are more closely related to a facet of Openness to Experience known as Intellect [85]. However, we focus primarily on links between Conscientiousness and cognitive control here, because the AMPD does not consider intellectual functioning, and thus working memory, to fall within the domain of personality pathology.
} 
tively low Conscientiousness is represented within the Disinhibition domain of the AMPD [51]. Disinhibition has been linked to variability in both behavioral and neurophysiological measures of error processing and inhibitory control [52]. For example, Disinhibition is associated with a reduction in the amplitude of the P3 event-related potential, a positive-going waveform that occurs following presentation of a salient stimulus in cognitive control tasks. Interestingly, P3 indices can be combined with behavioral performance measures and self-report ratings to model a cross-modal, latent Disinhibition factor [53].

From a dual systems perspective, adolescent risk-taking is conceptualized as a developmental imbalance in which the influence of the reward system outweighs a slower-developing cognitive control system. Behavioral studies have found that while many aspects of cognitive control are present early in life, they improve gradually over the course of development, remaining more variable in adolescence than in adulthood [54]. This mirrors the developmental trajectory of Conscientiousness, which tends to increase substantially in adolescence before rising more slowly through adulthood (though, it may also dip early in adolescence) [55]. Development of cognitive control depends on functional changes in the activity and connectivity of distributed regions, including dorsolateral prefrontal cortex (DLPFC), posterior parietal cortex, insula, and ACC [56]. For example, children engage the DLPFC more during inhibitory control tasks, with activation steadily declining into adulthood and mirroring performance improvements $[57,58]$. Interestingly, deactivating the DLPFC using transcranial magnetic stimulation leads to increased risk-taking on a gambling task [59], whereas activating DLPFC using electrical stimulation has the opposite effect [60]. Focal damage to the area has also been linked to lower self-reported Conscientiousness [61].

The dorsal ACC is another key region in the development of cognitive control. It tends to be more heavily recruited with age, particularly in response to errors during inhibitory control tasks $[57,58]$. Age-related increases in dorsal ACC activation may reflect developmental improvements in one's ability to effortfully attend to current task demands and adjust behavior accordingly as those demands change (perhaps via the recruitment of other control regions such as DLPFC) [62]. Conscientiousness is positively associated with dorsal ACC activation during inhibitory control tasks [63]. Likewise, Disinhibition has been linked to a reduced amplitude of the error-related negativity on go/no-go tasks; the error-related negativity is an event-related potential involved in error processing that has been localized to the ACC [64]. Changes in Conscientiousness also mediate the relationship between cortical thinning of the dorsal ACC during adolescence and measures of depression, anxiety, aggression, and risk-taking, consistent with the idea that poor inhibitory control is a transdiagnostic risk factor [65].

Changes in cognitive control over the course of development are tightly linked to changes in a set of highly overlapping functional brain networks - including the salience network (SN), cingulo-opercular network, and Rothbart and Posner's executive attention network [66] - all of which include the ACC and DLPFC. The basic architecture of these networks is in place early in development, but between-network connectivity strengthens throughout development, supporting improvements in cognitive control [67]. Consistent with this, network analyses show that prefrontal cognitive control regions break off into a distinct module from subcortical regions (including those involved in reward sensitivity) in individuals low in Conscientiousness [68]. The SN, whose central nodes include the dorsal ACC and anterior insula, has been linked to the detection of behaviorally relevant stimuli and the initiation of cognitive control [69]. Previous studies have shown that developmental increases in SN recruitment during inhibitory control tasks mediate age-related performance improvements [32]. Conscientiousness has been hypothesized to be related to functionally overlapping components of the salience and ventral attention networks [44], which Rueter and colleagues [70] collectively refer to as the "goal priority network." In a recent resting-state fMRI study, these authors found that Conscientiousness was associated with greater connectivity within part of the goal priority network that included the DLPFC, anterior insula, and dorsal ACC. Conscientiousness was also associated with greater coupling of these regions with functionally distinct subnetworks [70].

Disinhibition is also negatively associated with functional connectivity between the insula and DLPFC during inhibitory control [71], which suggests that the coordination of control-related regions may be critical to suppressing impulsive responses. Interestingly, cortical thickness of the insula is negatively correlated with both age and Conscientiousness, consistent with the idea that greater synaptic plasticity in the insula facilitates improved deliberation with age [72]. Conscientiousness may also be supported by better structural connectivity of the insula with limbic and prefrontal regions. For example, Lewis and colleagues [73] found that Conscientiousness was positively associated with higher fractional an- 
isotropy (a measure of structural connectivity) in the left uncinate fasciculus, a white matter tract that connects the insula, orbitofrontal cortex, anterior temporal cortex, and amygdala. Taken together, empirical studies consistently find that the cognitive control system develops gradually with age, is related to widespread changes in control-related brain circuits, and may be a key source of individual differences in Conscientiousness and Disinhibition. Thus, heterogeneity in the development of cognitive control and reward processing neurobehavioral systems likely contributes to normative age-related risk-taking. At the extremes, variation in the development of these systems may underlie more problematic impulsive behaviors that are typically observed in personality pathology.

\section{Linking Adolescent Neurocognitive Development to Dimensional Personality Pathology}

Thus far, we have reviewed evidence supporting a dual systems account of adolescent neurocognitive development and have related individual differences in these circuits to normative personality traits, namely Extraversion and Conscientiousness. To date, however, very few studies have explicitly linked the emergence of personality pathology with prevailing accounts of neurocognitive development. By removing the boundary between normal and abnormal functioning, the AMPD provides a useful foundation from which researchers can develop and test such accounts.

How might the AMPD capture maladaptive development of the reward processing and cognitive control systems? At least with respect to reward processing, this is a complicated question. The normal personality literature distinguishes between two interrelated facets of Extraversion: an affiliative component reflecting hedonic reward consumption (also known as "liking") and an agentic component that is more closely related to incentive motivation (also known as "wanting") [34, 44]. Recent evidence has shown that the Detachment domain of the AMPD is a slightly stronger marker of affiliative Extraversion (reversed) than agentic Extraversion [74], pointing to a potential gap in coverage that may require further consideration as the system is revised over time. On the other hand, there may also be substantive reasons for this gap. While some components of agentic Extraversion are robustly linked to risk for psychopathology, others show minimal associations [75]. Sensation-seeking is a lowerorder personality trait that equally blends Conscientiousness and agentic Extraversion, and it is robustly associ-

Adolescent Neurocognitive Development and the AMPD ated with externalizing problems [75]. This suggests incentive motivation may be more problematic when accompanied by at least some difficulties with top-down inhibitory control [76].

Interestingly, sensation-seeking exhibits a U-shaped developmental trajectory, peaking in adolescence in much the same way as ventral striatal activity on reward processing tasks [29]. Deviations from the typical Ushaped reward processing trajectory may be associated with the onset of externalizing problems in adolescence. For instance, one study found that smaller ventral striatum volumes in mid-adolescence predicted an increased likelihood of initiating substance use in a 2-year followup period [77]. In the same study, increases in reward sensitivity were associated with a greater likelihood of substance use initiation and with more self-reported alcohol use during the follow-up period [77].

Disruptions in reward circuitry during adolescence may also affect a host of other problematic behaviors that are more indirectly related to reward-seeking. For instance, activity in the ventral striatum following provocation predicts the magnitude of one's subsequent retaliation, suggesting that social status behaviors partly depend on reward-related circuitry [78]. Consistent with this, larger striatal volume in early adolescence is positively associated with aggression [79], potentially reflecting a disruption in the typical development of circuits that mediate reward-related aggression. Overall, these findings highlight the need for longitudinal cognitive neuroscience studies to address questions about the developmental trajectory of personality pathology in youth. For instance, do some adolescents exhibit time-limited personality pathology that remits once cognitive control systems exert a greater influence on behavior, while reward processing systems either plateau or decline? Does more persistent sensitivity of reward circuits predict maladaptive expressions of Extraversion in other youths? These are questions that can only be answered via longitudinal studies, preferably in high-risk developmental samples that capture the full range of maladaptive trait dimensions.

Contextualizing maladaptive cognitive control within the AMPD is more straightforward, as Disinhibition is closely related to both neural and behavioral indices of inhibitory control [53]. One AMPD facet particularly relevant to dual systems accounts is risk-taking, which was originally assigned to the Disinhibition domain but has a nearly equal negative cross-loading on Detachment (suggesting it may be the AMPD equivalent to sensation-seeking) [80]. Youths high on risk-taking may struggle to bal- 
ance the lure of immediately rewarding opportunities (e.g., going to a party, having sex, trying drugs) in adolescence with the sustained effort required to attain longerterm goals, including academic and occupational achievement, stable familial and romantic relationships, and maintaining a healthy lifestyle. Given its pattern of crossloadings, personality neuroscience researchers should consider how risk-taking depends on circuits related to both reward and cognitive control. For instance, connectivity between the dorsal striatum and inferior frontal gyrus (which is part of the goal priority network linked to Conscientiousness) is associated with an improved capacity to suppress approach responses to appetitive cues in teens and adults compared to children; only in adolescents, however, this frontostriatal coupling is also accompanied by greater ventral striatal activity [81]. This might suggest that risk-taking in adolescence reflects a biasing of cognitive control circuits related to Conscientiousness by reward signals that are encoded in the ventral striatum and more closely linked to Extraversion.

Of course, other circuits and traits that we did not cover here undoubtedly play a role in how adolescents navigate developmental challenges. For instance, another AMPD trait, Antagonism, has been linked to components of the default mode network implicated in mentalizing abilities [82] and may contribute to a devaluing of stable relationships during adolescence, in favor of short-term rewards (e.g., being more willing to manipulate or exploit a partner for immediate gain). In contrast, high scores on the AMPD's Negative Affect, coupled with risk-taking, could promote coping strategies meant to gain immediate relief from distress (e.g., self-harm, suicide attempts). The role of these traits in the development of personality pathology likely depends on the plasticity of functionally distinct networks during adolescence. For instance, networks supporting mentalizing abilities and social cognition continue to develop during adolescence [20], and extreme variations in those systems may play an important role in more interpersonal forms of personality pathology (e.g., rejection sensitivity, suspiciousness, or manipulativeness).

\section{Conclusions}

The dissemination of the AMPD and the broader shift toward dimensional conceptualizations of psychopathology in recent years are promising developments for researchers interested in the neurocognitive basis of personality pathology. By removing an arbitrary normal/ab- normal boundary and reframing personality pathology in terms of empirically derived traits, the AMPD helps to build a bridge between developmental studies of neurobehavioral systems and dimensional studies of traits. Recent evidence suggests that the AMPD has clinical utility, improving communication between patients, caregivers, and providers, easing diagnostic assessment for clinicians, and helping to guide clinical decision-making [83, 84]. Integrating developmental neuroscientific evidence into the AMPD can facilitate new insights into the mechanisms that fuel personality pathology and potentially lead to innovations in assessment and intervention. Here, we reviewed how two traits in the AMPD, Detachment and Disinhibition, can be used to connect the emergence of adolescent personality pathology with the development of reward and cognitive control systems. Moving forward, we hope that this kind of integration can be used to highlight areas in the AMPD that are in need for further elaboration and refinement. Incorporating evidence from multiple levels of analysis should improve the rigor and comprehensiveness of the AMPD, making it a more clinically useful nosology.

\section{Acknowledgement}

This work was funded by the National Institutes of Health (Grant No. R01-MH119399 and Grant No. R01-MH048463 [to M.N.H.], and Grant No. T32-MH016804 [to T.A.A.]). The funding agency had no role in the preparation, review, or approval of the manuscript or the decision to submit the manuscript for publication.

\section{Statement of Ethics}

This article was prepared in compliance with internationally accepted standards for research practice and reporting.

\section{Conflict of Interest Statement}

The authors have no conflicts to disclose.

\section{Author Contributions}

Both authors reviewed and approved the final version of this work. T.A.A. was primarily responsible for drafting the manuscript. M.N.H. contributed additional writing and revisions. 


\section{References}

1 Johnson JG, Cohen P, Kasen S, Skodol AE, Hamagami F, Brook JS. Age-related change in personality disorder trait levels between early adolescence and adulthood: a communitybased longitudinal investigation. Acta Psychiatr Scand. 2000 Oct;102(4):265-75.

2 Spear LP. Adolescent neurodevelopment. J Adolesc Health. 2013 Feb;52(2 Suppl 2):S713.

3 American Psychiatric Association. Diagnostic and statistical manual of mental disorders. 5th ed. Washington (DC), 2013. https://doi. org/10.1176/appi.books.9780890425596.

4 Clark LA. Assessment and diagnosis of personality disorder: perennial issues and an emerging reconceptualization. Annu Rev Psychol. 2007;58(1):227-57.

5 Krueger RF, Derringer J, Markon KE, Watson D, Skodol AE. Initial construction of a maladaptive personality trait model and inventory for DSM-5. Psychol Med. 2012 Sep;42(9): 1879-90.

6 Krueger RF, Hopwood CJ, Wright A, Markon KE. DSM-5 and the path toward empirically based and clinically useful conceptualization of personality and psychopathology. Clin Psychol Sci Pract. 2014;21(3):245-61.

7 Gunderson JG. Commentary on "Personality traits and the classification of mental disorders: toward a more complete integration in DSM-5 and an empirical model of psychopathology". Pers Disord. 2010 Apr;1(2):119-22.

8 Hopwood CJ. Interpersonal dynamics in personality and personality disorders. Eur J Pers. 2018 Sep;32(5):499-524.

9 Kotov R, Krueger RF, Watson D, Achenbach TM, Althoff RR, Bagby RM, et al. The Hierarchical Taxonomy of Psychopathology (HiTOP): A dimensional alternative to traditional nosologies. J Abnorm Psychol. 2017 May; 126(4):454-77.

10 Freeman HD, Gosling SD. Personality in nonhuman primates: a review and evaluation of past research. Am J Primatol. 2010 Aug;72(8): 653-71.

11 Depue RA, Lenzenweger MF. Toward a developmental psychopathology of personality disturbances: A neurobehavioral dimensional model. In: Cicchetti D, Cohen DJ, editors. Developmental neuroscience. Developmental psychopathology. Volume 2. 2nd ed. Hoboken (NJ): Wiley; 2015. pp. 762-96.

12 Kaess M, Brunner R, Chanen A. Borderline personality disorder in adolescence. Pediatrics. 2014 Oct;134(4):782-93.

13 Conway CC, Tackett JL, Skodol AE. Are personality disorders assessed in young people? Am J Psychiatry. 2017 Oct;174(10):1000-1.

14 Cicchetti D, Crick NR. Precursors and diverse pathways to personality disorder in children and adolescents. Dev Psychopathol. 2009; 21(3):683-5.
15 Shiner RL, Allen TA (Livesley J, Larstone R, editors). Handbook of Personality Disorders. Developmental psychopathology. 2nd ed. New York (NY): Guilford Press; 2018. pp. 309-23.

16 Sroufe LA. Considering normal and abnormal together: the essence of developmental psychopathology. Dev Psychopathol. 1990; 2(4):335-47.

17 Cicchetti D, Rogosch FA. A developmental psychopathology perspective on adolescence. J Consult Clin Psychol. 2002 Feb;70(1):6-20.

18 Soto CJ, John OP, Gosling SD, Potter J. Age differences in personality traits from 10 to 65 : big Five domains and facets in a large crosssectional sample. J Pers Soc Psychol. 2011 Feb; 100(2):330-48.

19 Eaton DK, Kann L, Kinchen S, Shanklin S, Flint KH, Hawkins J, et al. Youth risk behavior surveillance. United States; 2012.

20 Somerville LH. Special issue on the teenage brain: sensitivity to social evaluation. Curr Dir Psychol Sci. 2013 Apr;22(2):121-7.

21 Merikangas KR, He JP, Burstein M, Swanson SA, Avenevoli S, Cui L, et al. Lifetime prevalence of mental disorders in U.S. adolescents: results from the National Comorbidity Survey Replication - Adolescent Supplement (NCS-A). J Am Acad Child Adolesc Psychiatry. 2010;49(10):980-9.

22 Mercado MC, Holland K, Leemis RW, Stone DM, Wang J. Trends in emergency department visits for nonfatal self-inflicted injuries among youth aged 10 to 24 years in the United States, 2001-2015. JAMA. 2017 Nov; 318(19):1931-3.

23 Shulman EP, Smith AR, Silva K, Icenogle G, Duell N, Chein J, et al. The dual systems model: Review, reappraisal, and reaffirmation. Dev Cogn Neurosci. 2016 Feb;17:103-17.

24 Gore WL, Widiger TA. The DSM-5 dimensional trait model and five-factor models of general personality. J Abnorm Psychol. 2013 Aug;122(3):816-21.

25 Soto CJ. The little six personality dimensions from early childhood to early adulthood: mean-level age and gender differences in parents' reports. J Pers. 2016 Aug;84(4):409-22.

26 DeYoung CG, Allen TA. Personality neuroscience: A developmental perspective. In: McAdams DP, Shiner RL, Tackett JL, editors. Handbook of Personality Development. New York: Guilford Press; 2019. pp. 79-105.

27 Roberts BW, Walton KE, Viechtbauer W. Patterns of mean-level change in personality traits across the life course: a meta-analysis of longitudinal studies. Psychol Bull. 2006 Jan; 132(1): 1-25.

28 Urošević S, Collins P, Muetzel R, Lim K, Luciana $\mathrm{M}$. Longitudinal changes in behavioral approach system sensitivity and brain structures involved in reward processing during adolescence. Dev Psychol. 2012 Sep;48(5): 1488-500.
29 Steinberg L, Icenogle G, Shulman EP, Breiner $\mathrm{K}$, Chein J, Bacchini D, et al. Around the world, adolescence is a time of heightened sensation seeking and immature self-regulation. Dev Sci. 2018 Mar;21(2):1-14.

30 Galvan A, Hare T, Voss H, Glover G, Casey BJ. Risk-taking and the adolescent brain: who is at risk? Dev Sci. 2007 Mar;10(2):F8-14.

31 Silverman MH, Jedd K, Luciana M. Neural networks involved in adolescent reward processing: an activation likelihood estimation meta-analysis of functional neuroimaging studies. Neuroimage. 2015 Nov;122:427-39.

32 Hallquist MN, Geier CF, Luna B. Incentives facilitate developmental improvement in inhibitory control by modulating control-related networks. Neuroimage. 2018 May; 172(172):369-80.

33 Luciana M, Collins PF. Incentive motivation, cognitive control, and the adolescent brain: is it time for a paradigm shift? Child Dev Perspect. 2012 Dec;6(4):392-9.

34 Depue RA, Collins PF. Neurobiology of the structure of personality: dopamine, facilitation of incentive motivation, and extraversion. Behav Brain Sci. 1999 Jun;22(3):491517 .

35 Bromberg-Martin ES, Matsumoto M, Hikosaka O. Dopamine in motivational control: rewarding, aversive, and alerting. Neuron. 2010 Dec;68(5):815-34.

36 Schultz W. Behavioral dopamine signals. Trends Neurosci. 2007 May;30(5):203-10.

37 Glimcher PW. Understanding dopamine and reinforcement learning: the dopamine reward prediction error hypothesis. Proc Natl Acad Sci USA. 2011 Sep;108 Suppl 3:15647-54.

38 Cohen JR, Asarnow RF, Sabb FW, Bilder RM, Bookheimer SY, Knowlton BJ, et al. A unique adolescent response to reward prediction errors. Nat Neurosci. 2010 Jun;13(6):669-71.

39 Nussenbaum K, Hartley CA. Reinforcement learning across development: what insights can we draw from a decade of research? Dev Cogn Neurosci. 2019 Dec;40:100733.

40 Murty VP, Shah H, Montez D, Foran W, Calabro F, Luna B. Age-related trajectories of functional coupling between the VTA and nucleus accumbens depend on motivational state. J Neurosci. 2018 Aug;38(34):7420-7.

41 Sesack SR, Pickel VM. Prefrontal cortical efferents in the rat synapse on unlabeled neuronal targets of catecholamine terminals in the nucleus accumbens septi and on dopamine neurons in the ventral tegmental area. J Comp Neurol. 1992 Jun;320(2):145-60.

42 van Duijvenvoorde AC, Achterberg M, Braams BR, Peters S, Crone EA. Testing a dual-systems model of adolescent brain development using resting-state connectivity analyses. Neuroimage. 2016 Jan;124 Pt A:409-20. 
43 Larsen B, Verstynen TD, Yeh FC, Luna B. Developmental changes in the integration of affective and cognitive corticostriatal pathways are associated with reward-driven behavior. Cereb Cortex. 2018 Aug;28(8):2834-45.

44 Allen TA, DeYoung CG. Personality neuroscience and the five factor model. In: Widiger TA, editor. The Oxford Handbook of the Five Factor Model. New York. Oxford; 2017. pp. 1-63.

45 Braams BR, van Duijvenvoorde AC, Peper JS, Crone EA. Longitudinal changes in adolescent risk-taking: a comprehensive study of neural responses to rewards, pubertal development, and risk-taking behavior. J Neurosci. 2015 May;35(18):7226-38.

46 Kujawa A, Proudfit GH, Kessel EM, Dyson M, Olino T, Klein DN. Neural reactivity to monetary rewards and losses in childhood: longitudinal and concurrent associations with observed and self-reported positive emotionality. Biol Psychol. 2015 Jan; 104:41-7.

47 Bress JN, Hajcak G. Self-report and behavioral measures of reward sensitivity predict the feedback negativity. Psychophysiology. 2013 Jul;50(7):610-6.

48 Burani K, Mulligan EM, Klawohn J, Luking KR, Nelson BD, Hajcak G. Longitudinal increases in reward-related neural activity in early adolescence: evidence from event-related potentials (ERPs). Dev Cogn Neurosci. 2019 Apr;36:100620.

49 Luna B, Padmanabhan A, O'Hearn K. What has fMRI told us about the development of cognitive control through adolescence? Brain Cogn. 2010 Feb;72(1):101-13.

50 DeYoung CG. Cybernetic big five theory. J Res Pers. 2015;56:33-58.

51 Suzuki T, Griffin SA, Samuel DB. Capturing the DSM-5 alternative personality disorder model traits in the five-factor model's nomological net. J Pers. 2017 Apr;85(2):220-31.

52 Ribes-Guardiola P, Poy R, Patrick CJ, Moltó J. Electrocortical measures of performance monitoring from go/no-go and flanker tasks: differential relations with trait dimensions of the triarchic model of psychopathy. Psychophysiology. 2020 Jun;57(6):e13573.

53 Venables NC, Foell J, Yancey JR, Kane MJ, Engle RW, Patrick CJ. Quantifying inhibitory control as externalizing proneness: A crossdomain model. Clin Psychol Sci. 2018 Jul; 6(4):561-80.

54 Luna B, Garver KE, Urban TA, Lazar NA, Sweeney JA. Maturation of cognitive processes from late childhood to adulthood. Child Dev. 2004 Sep-Oct;75(5):1357-72.

55 Soto CJ, Tackett JL. Personality traits in childhood and adolescence: Structure, development, and outcomes. Curr Dir Psychol Sci. 2016;76(4):358-62.

56 Luna B, Marek S, Larsen B, Tervo-Clemmens $B$, Chahal R. An integrative model of the maturation of cognitive control. Annu Rev Neurosci. $2015 \mathrm{Jul} ; 38(1): 151-70$.

57 Velanova K, Wheeler ME, Luna B. Maturational changes in anterior cingulate and frontoparietal recruitment support the develop- ment of error processing and inhibitory control. Cereb Cortex. 2008 Nov; 18(11):2505-22.

58 Ordaz SJ, Foran W, Velanova K, Luna B. Longitudinal growth curves of brain function underlying inhibitory control through adolescence. J Neurosci. 2013 Nov;33(46):18109-24.

59 Knoch D, Gianotti LR, Pascual-Leone A, Treyer V, Regard M, Hohmann M, et al. Disruption of right prefrontal cortex by low-frequency repetitive transcranial magnetic stimulation induces risk-taking behavior. J Neurosci. 2006 Jun;26(24):6469-72.

60 Fecteau S, Knoch D, Fregni F, Sultani N, Boggio $\mathrm{P}$, Pascual-Leone A. Diminishing risktaking behavior by modulating activity in the prefrontal cortex: a direct current stimulation study. J Neurosci. 2007 Nov;27(46):12500-5.

61 Forbes CE, Poore JC, Krueger F, Barbey AK, Solomon J, Grafman J. The role of executive function and the dorsolateral prefrontal cortex in the expression of neuroticism and conscientiousness. Soc Neurosci. 2014;9(2):139-51.

62 Sadaghiani S, D'Esposito M. Functional characterization of the cingulo-opercular network in the maintenance of tonic alertness. Cereb Cortex. 2015 Sep;25(9):2763-73.

63 Brown SM, Manuck SB, Flory JD, Hariri AR. Neural basis of individual differences in impulsivity: contributions of corticolimbic circuits for behavioral arousal and control. Emotion. 2006 May;6(2):239-45.

64 Hall JR, Bernat EM, Patrick CJ. Externalizing psychopathology and the error-related negativity. Psychol Sci. 2007 Apr;18(4):326-33.

65 Vijayakumar N, Whittle S, Dennison M, Yücel M, Simmons J, Allen NB. Development of temperamental effortful control mediates the relationship between maturation of the prefrontal cortex and psychopathology during adolescence: a 4-year longitudinal study. Dev Cogn Neurosci. 2014 Jul;9:30-43.

66 Posner MI, Rothbart MK. Toward a physical basis of attention and self regulation. Phys Life Rev. 2009 Jun;6(2):103-20.

67 Marek S, Hwang K, Foran W, Hallquist MN, Luna B. The contribution of network organization and integration to the development of cognitive control. PLoS Biol. 2015 Dec; 13(12):e1002328.

68 Davis FC, Knodt AR, Sporns O, Lahey BB, Zald DH, Brigidi BD, et al. Impulsivity and the modular organization of resting-state neural networks. Cereb Cortex. 2013 Jun; 23(6):1444-52.

69 Menon V, Uddin LQ. Saliency, switching, at tention and control: a network model of insula function. Brain Struct Funct. 2010 Jun; 214(5-6):655-67.

70 Rueter AR, Abram SV, MacDonald AW 3rd, Rustichini A, DeYoung CG. The goal priority network as a neural substrate of Conscientiousness. Hum Brain Mapp. 2018 Sep;39(9): 3574-85.

71 Farr OM, Hu S, Zhang S, Li CS. Decreased saliency processing as a neural measure of Barratt impulsivity in healthy adults. Neuroimage. 2012 Nov;63(3):1070-7.
72 Churchwell JC, Yurgelun-Todd DA. Age-related changes in insula cortical thickness and impulsivity: significance for emotional development and decision-making. Dev Cogn Neurosci. 2013 Oct;6:80-6.

73 Lewis GJ, Cox SR, Booth T, Muñoz Maniega S, Royle NA, Valdés Hernández M, et al. Trait conscientiousness and the personality metatrait stability are associated with regional white matter microstructure. Soc Cogn Affect Neurosci. 2016 Aug;11(8):1255-61.

74 Allen TA, DeYoung CG, Bagby RM, Pollock B, Quilty LC. A hierarchical integration of normal and abnormal personality dimensions: structure and predictive validity in a heterogeneous sample of psychiatric outpatients. Assessment. 2020 Jun;27(4):643-56.

75 Watson D, Stasik SM, Ellickson-Larew S, Stanton K. Extraversion and psychopathology: A facet-level analysis. J Abnorm Psychol. 2015 May;124(2):432-46.

76 Rhodes JD, Colder CR, Trucco EM, Speidel C, Hawk LW Jr, Lengua LJ, et al. The interaction between self-regulation and motivation prospectively predicting problem behavior in adolescence. J Clin Child Adolesc Psychol. 2013; 42(5):681-92.

77 Urošević S, Collins P, Muetzel R, Schissel A, Lim KO, Luciana M. Effects of reward sensitivity and regional brain volumes on substance use initiation in adolescence. Soc Cogn Affect Neurosci. 2015 Jan;10(1):106-13.

78 Chester DS, DeWall CN. The pleasure of revenge: retaliatory aggression arises from a neural imbalance toward reward. Soc Cogn Affect Neurosci. 2016 Jul;11(7):1173-82.

79 Yang Y, Joshi SH, Jahanshad N, Thompson PM, Baker LA. Neural correlates of proactive and reactive aggression in adolescent twins. Aggress Behav. 2017 May;43(3):230-40

80 Wright AG, Thomas KM, Hopwood CJ, Markon KE, Pincus AL, Krueger RF. The hierarchical structure of DSM-5 pathological personality traits. J Abnorm Psychol. 2012 Nov; 121(4):951-7.

81 Somerville LH, Hare T, Casey BJ. Frontostriatal Maturation Predicts Cognitive Control Failure to Appetitive Cues in Adolescents. J Cogn Neurosci. 2011 Sep;23(9):2123-34.

82 Allen TA, Rueter AR, Abram SV, Brown JS, DeYoung CG. Personality and neural correlates of mentalizing ability. Eur J Pers. 2017 Nov-Dec;31(6):599-613.

83 Rodriguez-Seijas C, Ruggero C, Eaton NR, Krueger RF. The DSM-5 alternative model for personality disorders and clinical treatment: A review. Curr Treat Options Psychiatry. 2019 Dec;6(4):284-98.

84 Milinkovic MS, Tiliopoulos N. A systematic review of the clinical utility of the DSM-5 section III alternative model of personality disorder. Personal Disord. 2020. DOI: https://doi. org/10.1037/per0000408.

85 DeYoung CG, Quilty LC, Peterson JB, Gray JR. Openness to experience, intellect, and cognitive ability. J Pers Assess. 2014;96(1): 46-52. 